\title{
Explicating numerical information: when and how fingers support (or hinder) number comprehension and handling
}

\author{
Sieghard Beller* and Andrea Bender \\ Department of Psychology, Albert-Ludwigs-University, Freiburg, Germany \\ *Correspondence: beller@psychologie.uni-freiburg.de
}

\section{INTRODUCTION}

Numbers are of enormous significance for modern society. They form the basis of currency and economic systems, of measurement and calculation, of engineering and the natural sciences, and, as a matter of course, lie at the heart of mathematics. Therefore, teaching mathematical skills plays an important role in preschool and school education. However, before children are able to perform their first symbolic algorithms such as multi-digit addition and multiplication they must have mastered two representational number systems: a verbal system (e.g., English number words) and a notational system (e.g., Arabic digits).

The main competence that children have to acquire with these systems is to represent and handle the numerical information internally (Zhang and Norman, 1995). Using one's fingers for numerical tasks may indicate that parts of the internal processes still require external support and are not mastered adequately, but it would be erroneous to infer that finger strategies are not worthy of support. On the contrary: we argue that one's fingers, applied properly, provide a natural, and readily available toolkit for modeling numerical information and reflecting on numerical concepts (cf. Fuson and Secada, 1986; Carpenter et al., 1999; Wright et al., 2002; Guha, 2006; Andres et al., 2008). This position is exemplified for the acquisition of the verbal number system and for verbal processes involved in counting and calculating. Following Zhang and Norman's (1995) representational analysis of notational systems, we analyze which features of the verbal system can be accessed externally, which have to be represented internally, and how this may be supported - or hindered - by finger counting strategies.

\section{LEARNING THE VERBAL NUMBER SYSTEM}

Number words refer to the (theoretically) infinite set of natural numbers, the positive integers. This set defines a ratio dimension, providing category (or nominal) information for judging whether or not two numbers are equal, magnitude (or ordinal) information for judging whether a number is smaller or greater than another, and interval as well as ratio information for assessing differences between and proportions of numbers.

Number words are distributed representations in that they make available some of this information externally - ready to be picked up by auditory or visual processes - while other information needs to be retrieved from memory and is thus available only internally (Zhang and Norman, 1995). In the case of number words, category information on whether a word is equal to or different from another can be perceived externally, whereas magnitude, interval, and ratio information cannot and therefore must be learned in order to be available. This is difficult not only because number is an abstract concept (Wiese, 2003), but also because three different kinds of numerical relations are involved (for a micro-genetic single case study of how the first number words are acquired, see Palmer and Baroody, 2011). One's own fingers support essential learning processes: in the beginning, they help to differentiate numerals by relating different phonological patterns to different finger patterns; later on, they help in the acquisition of numerical information as the fingers provide a ratio dimension of at least 10 units.

Number words constitute a numerical system with distinct properties such as dimensionality and regularity (Bender and Beller, 2011). While one-dimensional systems use a separate lexeme for each number, twodimensional systems use lexemes only for the primary counting sequence and for the powers of the base. English, for example, contains a decimal system with nine primary numerals ("one" to "nine") and numerals for the powers of base 10 ("ten," "hundred," "thousand," etc.). From these, all other numerals are composed according to the addition and multiplication principle (with some exceptions in regularity). When hearing a number word, recurring phonological patterns provide us with externally perceivable category information on the dimensional structure of the system, but again, the numerical information is not externally available and has to be learned (e.g., that "two hundred and two" is $2 \times 100+2$ ). Likewise, finger counting systems can differ in dimensionality: in a onedimensional system such as our 10-finger sequence each finger is counted separately. The Indian merchant system (Ifrah, 1985) is two-dimensional with base 5: the primary sequence (from one to five) is counted on one hand, the multiples of the base $(5,10,15$, 20 , and 25) on the other (for this and other examples see Bender and Beller, submitted). Finger systems like this indicate that a new counting cycle has to start when the base is reached, and hence can support the distinction between base and power. Ensuring this supporting function, however, presupposes a structural match between the finger and the verbal system in terms of dimensionality, base, and regularity; mismatches in these regards slow down the learning process (Fuson and Kwon, 1991; Miller et al., 1995). Such mismatches are generated by irregular number words (like "twelve" instead of *ten-and-two) and digit inversion (like "fourteen" instead of *ten-and-four) as in verbal English, or when the finger counting system uses a (sub-) base different from the verbal system (cf. Domahs et al., 2010; Klein et al., 2011).

The verbal number system, once acquired, is not only used to refer to cardinal numbers, but also for counting and calculating. The next section discusses how these processes might be supported or hindered by finger counting systems.

\section{LEARNING TO COUNT AND CALCULATE}

Counting is typically performed with recourse to the verbal number sequence. The acquisition of the counting routine 
takes children several years, but eventually enables them to start counting from any number, proceed forward and backward easily, and extract its numerical meaning (Fuson, 1988; Wynn, 1992; Wiese, 2003). Five principles need to be learned (Gelman and Gallistel, 1978): (a) To each object, one number word is assigned (one-to-one principle); (b) the order of the objects is irrelevant; (c) the order of the number words is fixed; (d) the numeral for the last object represents the cardinality of the set; and (e) all sorts of objects can be counted in the same way. This learning process can be affected by finger activities in different ways: fingers are external tokens that can themselves be counted. Different from words, which fade away and must be memorized, fingers are permanently visible for perceptual processes and provide magnitude, interval, and ratio information. Typically, fingers are used in a stable order (Wiese, 2003; Lindemann et al., 2011), yet this yields a trade-off: it facilitates access to the number words in their correct order (principle c), but - as fingers tend to be paired with the same numerals - may conceal that neither the order nor the kind of objects to be counted are relevant (principles b and e). Finally, fingers can be used for book-keeping and thus for taking some load off from memory. This book-keeping, as well as implementation of the one-to-one principle, is supported more strongly, when children are allowed to gesture (Alibali and DiRusso, 1999), whereas passive hand movements tend to disrupt counting strategies, even in adults (Imbo et al., 2011).

Relieving memory is even more important when it comes to calculation. Mathematical algorithms like those for multi-digit addition and multiplication are taught in the first school years. They are communicated verbally, but operate on the Arabic digits. Several of their sub-processes involve language (Dehaene, 1992), for example, single digit calculations based on the addition and multiplication tables. Some of these are known to be supported by finger activities when children are not yet able to retrieve the results directly from memory. The first finger strategy typically used for addition problems like $3+5$ is the "sum" strategy: hold three fingers up, hold five additional fingers up, and then count them all. Later on, children use their fingers adaptively and discover various shortcuts like count from the first addend (for $3+5$ : "four, five, six, seven, eight") or count from the largest addend ("six, seven, eight"; Siegler and Jenkins, 1989).

For the numbers 1-10, a decimal system encompasses 55 basic additions and multiplications each; the highest sum is 20 , the highest multiple 100. Our classic finger system with 10 as limiting number provides for only 25 additions and 15 multiplications. In order to fully cover the basic operations, the limiting number needs to be extended (for respective strategies see Guha, 2006; Bender and Beller, submitted).

Furthermore, finger counting systems are unsuitable for depicting negative numbers, which may result from subtraction (e.g., 3-7). After all, as concrete tokens, fingers are either present (positive) or absent (zero), but not negative.

\section{CONCLUSION}

The acquisition of the verbal number sequence is an essential part of learning to count and an important prerequisite for mathematical education, often accompanied by finger counting strategies. Although finger counting competencies are not indispensable for the development of numerical abilities (Crollen et al., submitted), finger-training was shown to increase children's numerical performance, for instance, in quantification tasks (Gracia-Bafalluy and Noël, 2008). It is thus not surprising that imprints of finger counting systems can be found in children's early number representations (Domahs et al., 2008), and even in adults' finger-digit mappings on a computer keyboard (Di Luca et al., 2006).

Based on our analysis, however, we identified some factors that might also hinder the initial learning process: structural mismatches (e.g., in base and dimensionality) between the verbal and the finger counting sequence, the limited extent of finger counting, and too strong an association between the number words and specific objects (the fingers). While some of these problems are inherent in finger counting in general, others might be reduced by choosing an appropriate system carefully (e.g., a two-dimensional finger counting system for a two-dimensional verbal system). Such efforts appear to be worthwhile, as the prototypical finger counting systems come with at least one crucial advantage: they provide a visible and easy to manipulate set of "objects," which helps to model and to internalize all the numerical information that is not externally represented in the arbitrary symbols of number words and digits.

\section{REFERENCES}

Alibali, M. W., and DiRusso, A. A. (1999). The function of gesture in learning to count: more than keeping track. Cogn. Dev. 14, 37-56.

Andres, M., Di Luca, S., and Pesenti, M. (2008). Finger counting: the missing tool? Behav. Brain Sci. 31, 642-643.

Bender, A., and Beller, S. (2011). "Numerical cognition and ethnomathematics," in A Companion to Cognitive Anthropology, eds D. Kronenfeld, G. Bennardo, V. C. de Munck, and M. Fischer (Cambridge: Blackwell), 270-289.

Carpenter, T. P., Fennema, E., Franke, M. L., Levi, L., and Empson, S. B. (1999). Children's Mathematics: Cognitively Guided Instruction. Portsmouth: Heinemann.

Dehaene, S. (1992). Varieties of numerical abilities. Cognition 44, 1-42.

Di Luca, S., Granà, A., Semenza, C., Seron, X., and Pesenti, M. (2006). Finger - digit compatibility in Arabic numeral processing. Q. J. Exp. Psychol. (Colchester) 59, 1648-1663.

Domahs, F., Krinzinger, H., and Willmes, K. (2008). Mind the gap between both hands: evidence fro internal finger-based number representations in children's mental calculation. Cortex 44, 359-367.

Domahs, F., Moeller, K., Huber, S., Willmes, K., and Nuerk, H.-C. (2010). Embodied numerosity: implicit handbased representations influence symbolic number processing across cultures. Cognition 116, 251-266.

Fuson, K. C. (1988). Children's Counting and Concepts of Number. New York: Springer.

Fuson, K. C., and Kwon, Y. (1991). “Chinese-based regular and European irregular systems of number words: the disadvantages for English-speaking children," in Language in Mathematical Education, eds K. Durkin and B. Shire (Milton Keynes: Open University Press), 211-226.

Fuson, K. C., and Secada, W. G. (1986). Teaching children to add by counting-on with one-handed finger patterns. Cogn. Instr. 3, 229-260.

Gelman, R., and Gallistel, C. R. (1978). The Child's Understanding of Number. Cambridge: Harvard University Press.

Gracia-Bafalluy, M., and Noël, M. P. (2008). Does fingertraining increase young children's numerical performance? Cortex 44, 368-375.

Guha, S. (2006). Using mathematics strategies in early childhood education as a basis for culturally responsive teaching in India. Int. J. Early Years Edu. 14, 15-34. Ifrah, G. (1985). From One to Zero. New York: Viking.

Imbo, I., Vandierendonck, A., and Fias, W. (2011). Passive hand movements disrupts adults' counting strategies. Front. Psychol. 2, 201. doi: 10.3389/ fpsyg.2011.00201

Klein, E., Moeller, K., Willmes, K., Nuerk, H. C., and Domahs, F. (2011). The influence of implicit hand-based representations on mental 
arithmetic. Front. Psychol. 2:197. doi: 10.3389/ fpsyg.2011.00197

Lindemann, O., Alipour, A., and Fischer, M. H. (2011). Finger counting habits in middle-Eastern and Western individuals: an online survey. J. Cross Cult. Psychol. $42,566-578$.

Miller, K., Smith, C. M., Zhu, J., and Zhang, H. (1995). Preschool origins of cross-national differences in mathematical competence: the role of number-naming systems. Psychol. Sci. 6, 56-60.

Palmer, A., and Baroody, A. J. (2011). Blake's development of the number words "one," "two," and "three." Cogn. Instr. 29, 265-296.
Siegler, R. S., and Jenkins, E. (1989). How Children Discover New Strategies. Hillsdale, NJ: Lawrence Erlbaum Associates.

Wiese, H. (2003). Numbers, Language, and the Human Mind. Cambridge: Cambridge University Press.

Wright, R., Martland, J., Stafford, A. K., and Stanger, G. (2002). Teaching Number:Advancing Children's Skills and Strategies. London: Paul Chapman.

Wynn, K. (1992). Children's acquisition of the number words and the counting system. Cogn. Psychol. 24, 220-251.

Zhang, J., and Norman, D. A. (1995). A representational analysis of numeration systems. Cognition 57, 271-295.
Received: 19July 2011; accepted: 18 August 2011; published online: 09 September 2011.

Citation: Beller S and Bender A (2011) Explicating numerical information: when and how fingers support (or hinder) number comprehension and handling. Front. Psychology 2:214. doi: 10.3389/ fpsyg.2011.00214

Copyright $\odot 2011$ Beller and Bender. This is an open-access article subject to a non-exclusive license between the authors and Frontiers Media SA, which permits use, distribution and reproduction in other forums, provided the original authors and source are credited and other Frontiers conditions are complied with. 